\title{
Can Sitaglipten Attenuate Hypertension, Myocardial Changes and Vascular Reactivity Induced by Long Term Blockade of Nitric Oxide Synthesis in the Rat?
}

\author{
Mervat E. Mohamed \\ Umelqura University, Makkah Elmokaramah, Saudi Arabia \\ Email: mervat vip@yahoo.com
}

Received 23 May 2014; revised 23 June 2014; accepted 8 July 2014

Copyright (C) 2014 by author and Scientific Research Publishing Inc. This work is licensed under the Creative Commons Attribution International License (CC BY). http://creativecommons.org/licenses/by/4.0/

(c) (i) Open Access

\section{Abstract}

Background: Glucagon-like peptide-1 (GLP-1) is an incretin hormone with insulinotropic properties that regulates glucose metabolism. GLP-1 receptors are the most extensively key modulators of lipid and glucose homeostasis. They are predominantly expressed in adipose tissues, some non adipose tissues including heart, kidney, spleen, and all relevant cells of the vasculature: endothelial cells, smooth muscle cells, and macrophages. The vascular distribution suggests their involvement in the control of cardiovascular function. Objective: The present experiment was designed to study the effect of sitaglipten alone or in combination with captopril on blood pressure, antioxidant enzymes, vascular reactivity and cardiac hypertrophy in NG-nitro-L-arginine methylester (L-NAME) induced hypertension in rats. Methods: One hundred male albino rats weighing from 150 - $200 \mathrm{~g}$ were included in this study. Rats were divided into two main groups. Group I, $(20$ rats) served as a control group for group II, and received $1 \mathrm{ml}$ of physiological saline (0.9\%), orally for seven weeks. Group II: hypertensive group, (80 rats) was given daily L-NAME in a dose of 40 $\mathrm{mg} / \mathrm{kg}$ orally for seven weeks. Rats were further subdivided into A, B, C, and D, each of 20 rats. Group-A, received $1 \mathrm{ml}$ of distilled water daily orally for six weeks, starting one week after L-NAME administration. Groups B, C and D were treated with daily sitaglipten $(10 \mathrm{mg} / \mathrm{kg} \mathrm{b.wt}$. orally) and captopril $(100 \mathrm{mg} / \mathrm{kg}$ b.wt. orally), alone or together for six weeks. Blood pressure, serum tumor necrosis factor- $\alpha$ (TNF- $\alpha$ ), body weight (BW) and heart weight (HW) were measured. Malondialdehyde (MDA) and reduced glutathione (GSH) were estimated in cardiac tissues. Thoracic aorta was isolated and the aortic rings were allowed to achieve maximal tension by cumulative addition of phenylephrine (PE) (10-9-10-5 M) to the bath solution. Results: Sitaglipten and captopril, alone or together produced significant decreases in blood pressure and TNF- $\alpha$. Higher oxidative stress accompanying hypertension was significantly reduced by sitaglipten and captopril treatment. The results showed that both drugs significantly attenuated the augmented contractile response to PE 
in hypertensive rats. In addition, they inhibited the cardiac hypertrophy (reduction in HW/BW ratio). Conclusion: These data suggest that DPP4 inhibitor (sitaglipten) "is away from being insulinotropic and regulates glucose metabolism", contributes to normal regulation of blood pressure and exerts protective effects in hypertension via many mechanisms, as inhibition of generation of free radicals.

\title{
Keywords
}

\author{
Glucagon-Like Peptide-1, Glucagon-Like Peptide-1 Receptor, Incretin, Diabetes, Blood Pressure, \\ Heart Failure, Vasodilatation, Sympathetic Activation, Blood Pressure, L-Name, Sitaglipten, Renin \\ Angiotensin System, Captopril
}

\section{Introduction}

Hypertension is a key risk factor for cardiovascular disease and kidney failure. Congestive heart failure with left ventricular (LV) dysfunction is often found in patients with hypertension [1]. The transition from LV wall hypertrophy compensatory for abnormal wall stress to overt heart failure has long been recognized, but the underlying mechanisms remain poorly understood. However, it is known that during the development of this transition insulin resistance, cardiac glucose uptake is down-regulated, angiotensin-converting enzyme (ACE) levels increase, and the reninangiotensin aldosterone system (RAAS) becomes hyperactivated [2] [3]. Heart failure and diabetes are intrinsically linked. Diabetes is a risk factor for coronary atherosclerosis leading to myocardial ischemia and infarction. Diabetes also causes cardiomyopathy independent of coronary atherosclerosis. Clinical presentation involved diastolic dysfunction characterized by abnormal LV relaxation, reduced systolic function and increased myocardial reflectivity, and elevated insulin resistance [4].

Hypertension and diabetes are the two leading causes of many cardiac diseases. Drugs that improve glucose uptake and glucose oxidation have cardioprotective effects and can attenuate subsequent cardiac disease [3]. Glucagon-like peptide-1 (GLP-1) is an incretin hormone with insulinotropic properties that regulates glucose metabolism [5]. GLP-1 receptor agonists can attenuate insulin resistance and improve glycemic control in patients with type II diabetes. Intravenous infusion of GLP-1 in patients with acute myocardial infarction for 72 hours after successful angioplasty reportedly improved cardiac function [6]. In Dahl salt-sensitive (DSS) hypertensive rats, GLP-1 attenuated the development of hypertension and cardiac remodeling, and improved cardiac functionality [7]. Sitaglipten is an incretin enhancer that shares many glucoregulatory properties with GLP-1. It enhances glucose-dependent insulin secretion, enhances glucose-dependent suppression of inappropriately high glucagon secretion, slows gastric emptying, and reduces food intake [8]. In diabetic model, dipeptidyl peptidase IV can promote $\beta$-cell proliferation and islet neogenesis from precursor cells [9]. NG-nitro-L-arginine methyl ester (L-NAME) induces a dose-dependent increase in bloodpressure (BP) associated with a decrease in the cGMP content of the arterial wall. The L-NAME model evolves in 2 stages: an early compensated stage characterized by high BP and a later accelerated stage associated with diastolic heart dysfunction characterized by LV hypertrophy and increased LV myocardial thickness and stiffening and the development of endorgan damage. Chronic blockade of NO synthase (NOS) can activate the expression of different genes in the arterial wall, such as inducible (i) isoform type II cyclooxygenase, and is associated with the accumulation of endothelial macrophages [10] [11].

The purpose of the present study was to determine whether hypertension, vascular and cardiac dysfunction in rats induced by L-NAME could be attenuated by the sitaglipten, also, to detect any benefit from the combination of sitaglipten and captopril on the tested parameters.

\section{Methods}

The ethical committee for conduction of animal studies at the pharmacology department approved the experimental protocol and all animals were cared for in accordance with the principles and guidelines of the Animal Care as outlined in the "Guide to the Care and Use of Experimental Animals". 


\subsection{Experimental Animals}

The present study was carried out on one hundred male albino rats of body weight ranging from 150 - 200 gm. The rats were obtained from physiology department, Faculty of Medicine, Alexandria University. The rats were kept in the animal house in metal cages under standard conditions of light and temperature, fed normal laboratory diet and had free access to water.

\subsection{Experimental Design}

The animal was randomly divided into the following groups:

Group I: Normal control group (20 rats).This group received $1 \mathrm{ml}$ of physiological saline (0.9\%) daily orally for 7 weeks. This group served as a control group for group II.

Group II: Experimental hypertensive model, (80 rats): Rats received oral NG-nitro-L-arginine methyl ester (L-NAME) (Sigma Chemical Co., Switzerland), in a dose of $40 \mathrm{mg} / \mathrm{kg}$ daily for seven weeks [12]. This group was further subdivided into 4 subgroups, each of 20 rats.

A-Untreated (hypertensive) group, received $1 \mathrm{ml}$ of $2 \%$ gum acacia (Arabic Laboratory Equipment Co.), daily orally following the L-NAME by one week, for six weeks. This group served as a control group for the drug-treated groups: II-B, II-C and II-D.

B-Sitaglipten treated group, rats were received sitaglipten (Sigma, St. Louis, MO) in a dose of $10 \mathrm{mg}$ per $\mathrm{kg}$ of body weight orally daily [13] for six weeks.

C-Captopril treated group, rats were received captopril in a dose of $100 \mathrm{mg}$ per $\mathrm{kg}$ of body weight orally daily [14] for six weeks.

D-Sitaglipten and captopril treated group, rats were received both drugs in the same previous doses and duration. The drugs were administered after being dissolved in $1 \mathrm{ml}$ of distilled water.

At the end of the experiment, the rats were fasted for 18 - 20 hours with free access to water. Rats were anesthetized with pentobarbital sodium in a dose of $(40 \mathrm{mg} / \mathrm{kg}$ b.wt.) weighed and blood samples were taken using capillary tubes introduced into the medial retro-orbital venous plexus [15]. Blood samples were centrifuged for 15 minutes at $3000 \mathrm{rpm}$. Sera were separated and stored at $-20^{\circ} \mathrm{C}$ until being used. After isolation of blood samples, each rat was sacrificed, thoracic aorta was isolated and hearts were rapidly excised, washed immediately with ice-cold saline, weighed and used to assess the hypertrophy and oxidative stress.

\subsection{Parameters Measured}

1)-Blood pressure: Systolic blood pressure (SBP) was measured by the invasive method after LNAME-induced hypertension once a week during the 6 weeks of the follow-up [16].

2)-Serum tumor necrosis factor-alpha (TNF- $\alpha$ ) concentration using the cytoscreen Rat Tumor Necrosis Factor-alpha ELISA kit (Biosource-California-USA) [17].

3)-Determination of malondialdehyde (MDA) an index of oxidative stress, in cardiac homogenate [18].

4)-Estimation of reduced glutathione (GSH) an index of endogenous antioxidant, in cardiac homogenate [19].

5)-Vascular reactivity study [20].

6)-Body weight, heart weight and heart weight/body weight ratio, an index of cardiac hypertrophy [21].

\subsection{Determination of Blood Pressure [16]}

Rats were anesthetized with pentobarbital sodium (50 mg/kg i.p.). Supplemental anesthesia was administered as needed. With the use of aseptic techniques, the femoral artery was dissected, and then a small opening was made in the artery by the means of very fine scissors (or tip of pediatric cannula). The PE catheter ( $5.5 \mathrm{~cm}$ of a PE 10 catheter connected to $13 \mathrm{~cm}$ of PE50 catheter) was introduced into the femoral artery up to the site of connection between the PE 10 and the PE50 catheters. Then a tunnel was made starting from the groin region, passing by the back of the rat and ending between the two scapulae using a tunneling device, where a small opening was made in the skin to exteriorize the catheter. The catheter was secured in place at 2 positions $0.5 \mathrm{~cm}$ apart by suturing it to the thigh muscle, then it was flushed with heparinized saline before closing the wound. The exteriorized catheter was clamped as near as possible from the rat body, excess length was cut, then it was plugged with a pin and the clamp was released. 


\subsection{Determination of Malondialdehyde (MDA) [18]}

Rat heart was weighed \& homogenized with cold $1.15 \% \mathrm{Kcl}$ to make $10 \%$ (w/v) homogenate. $0.2 \mathrm{ml}$ homogenate was added to $8.1 \%$ sodium dodecyl sulphate (SDS), $20 \%$ acetic acid solution adjusted to $\mathrm{pH} 3.5$, and 0.8 thiobarbituric acid (TBA).The mixture was made up to $4.0 \mathrm{ml}$ with distilled water, and then heated in a water bath at 95 for 1 hour. After cooling, $1 \mathrm{ml}$ distilled water and $5.0 \mathrm{ml}$ of n-butanol-pyridine (15:1; v/v) mixture was added. The absorbance of the organic layer was measured at $532 \mathrm{~nm}$. A standard curve was constructed using different concentrations of 1,1,3,3-tetramethoxypropane in ethanol. The concentration of MDA in the sample was determined in $\mathrm{n} \mathrm{mol} / \mathrm{g}$ tissue.

\subsection{Estimation of Reduced Glutathione (GSH) [18]}

This method was based on the development of a yellow color when 5,5' dithio-2nitrobenzoic acid (DTNB) is added to sulfahydryl compounds.0.2ml heart homogenate in ice-cold 3\% metaphosphoric acid was added to 1.8 $\mathrm{ml}$ distilled water. Then $3 \mathrm{ml}$ of the precipitating solution (1.67 g glacial metaphosphoric acid, $0.2 \mathrm{~g}$ EDTA, and $30 \mathrm{~g}$ of sodium chloride per $100 \mathrm{ml}$ distilled water) was added. The mixture was allowed to stand for 5 min and then filtered. $2 \mathrm{ml}$ of the filtrate was added to $0.3 \mathrm{M}$ Na2HPO4 solutions. In the spectrophotometer cuvette, $0.04 \%$ DTNB was added. The stable color was read at $412 \mathrm{~nm}$. Standard curve was constructed using serial dilutions of stock GSH standard. GSH level was expressed as $\mathrm{n} \mathrm{mol} / \mathrm{g}$ tissue.

\subsection{Vascular Reactivity Study [20]}

For measurement of vascular responses, the descending thoracic aorta of rats was isolated immediately after decapitation and carefully cleaned from fat and connective tissues. The aorta was cut into rings of $4 \mathrm{~mm}$ in length, placed between 2 stainless steel hooks and mounted in a $50 \mathrm{ml}$ organ bath containing Krebs-Henseleit solution at $37^{\circ} \mathrm{C}$ continuously bubbled with a $95 \% \mathrm{O}_{2}-5 \% \mathrm{CO}_{2}$ mixture ( $\mathrm{pH} 7.4$ ). The rings were equilibrated for $90 \mathrm{~min}$ with a resting tension of $2 \mathrm{~g}$. Phenylephrine (PE) was added in a cumulative manner (10-9-10-5 M) until a maximum response expressed as grams of tension (g) was achieved. The force of contraction was measured with an isometric force-displacement transducer (Washington type D1, Bioscience, U.K.) and recorded on a polygraph (Washington 300 MD2 C, Bioscience, U.K.).

\subsection{Statistical Analysis [22]}

Data were expressed as means with their corresponding standard deviations (SD). One way analysis of variance (ANOVA or F-test) was used to compare more than two means. Then the data were subjected to least significant difference (LSD) test.

\section{Results}

\subsection{Blood Pressure}

Administration of L-NAME significantly increased blood pressure of untreated group. There was a highly significant reduction on systolic blood pressure after sitaglipten treatment (Table 1, Figure 1).

\subsection{Serum TNF- $\alpha$ Concentration}

In L-NAME untreated group, TNF- $\alpha$ concentration was significantly increased when compared to normal control group. Treatment with sitaglipten and captopril separately or in combination reduced the concentration of TNF- $\alpha$ when compared to the corresponding groups (Table 1, Figure 2).

\subsection{Malondyaldehyde (MDA) and Reduced Glutathione (GSH) in Cardiac Tissue}

Oxidative stress as shown by MDA measurement was significantly increased in cardiac tissues (Table 1, Figure 3), while GSH was significantly decreased in hypertensive untreated group (Table 1, Figure 4). Treatment with sitaglipten and captopril separately or in combination reduced the level of MDA and increased endogenous antioxidants GSH when compared to the corresponding groups. 
Table 1. Effect of oral administration of sitaglipten and captopril separately or in combination daily for six weeks on systolic blood pressure, serum tumor necrosis factor-alpha (TNF- $\alpha$ ), malondyaldehyde (MDA) and reduced glutathione (GSH) in L-NAME-induced hypertensive rats (Mean $\pm \mathrm{SD}$ ).

\begin{tabular}{|c|c|c|c|c|}
\hline \multirow[b]{2}{*}{$\begin{array}{l}\text { Parameters } \\
\text { Group Studied } \\
(\mathrm{N}=20)\end{array}$} & \multirow[b]{2}{*}{$\begin{array}{l}\text { Systolic Blood Pressure } \\
\text { (mmHg) }\end{array}$} & \multirow{2}{*}{$\begin{array}{l}\text { Serum Tumor Necrosis } \\
\text { Factor-Alpha (TNF- } \alpha \text { ) } \\
\text { Concentration (ng/ml) }\end{array}$} & \multicolumn{2}{|c|}{ Myocardial Homogenate } \\
\hline & & & $\begin{array}{c}\text { Reduced Glutathione } \\
\text { (GSH) } \\
\text { ( } \mu \mathrm{mol} / \mathrm{g} \text { Tissue) }\end{array}$ & $\begin{array}{c}\text { Malondyaldehyde } \\
\text { (MDA) } \\
\text { (mol/g Tissue) }\end{array}$ \\
\hline Normal control gp. & $131 \pm 4.5$ & $6.12 \pm 0.34$ & $100.42 \pm 3.79$ & $4.19 \pm 0.3$ \\
\hline Hypertensive gp. & $190 \pm 5.9^{\mathrm{ac}}$ & $20.22 \pm 0.67^{\mathrm{ac}}$ & $411.23 \pm 5.21^{\text {ac }}$ & $2.11 \pm 0.2^{\mathrm{ac}}$ \\
\hline Sitaglipten treated gp. & $170 \pm 4.2^{\mathrm{abc}}$ & $15.69 \pm 0.73^{\mathrm{abc}}$ & $200.05 \pm 4.99^{\mathrm{abc}}$ & $3.01 \pm 0.1^{\mathrm{abc}}$ \\
\hline Captopril treated gp. & $155 \pm 3.9^{\mathrm{abc}}$ & $14.31 \pm 0.69^{\mathrm{abc}}$ & $150.39 \pm 6.69^{\mathrm{abc}}$ & $3.05 \pm 0.2^{\mathrm{abc}}$ \\
\hline $\begin{array}{l}\text { Sitaglipten and captopril } \\
\text { treated gp. }\end{array}$ & $132 \pm 3.3^{b}$ & $9.84 \pm 0.92^{\mathrm{ab}}$ & $121.21 \pm 7.53^{\mathrm{ab}}$ & $4.08 \pm 0.3^{\mathrm{b}}$ \\
\hline $\mathrm{F}(\mathrm{p})$ & $323.026^{*}(<0.001)$ & $610.160^{*}(<0.001)$ & $4702.247^{*}(<0.001)$ & $137.52^{*}(<0.001)$ \\
\hline
\end{tabular}

F: F test (ANOVA); a: Significant as compared to normal control group; b: Significant as compared to hypertensive group; c: Significant as compared to sitaglipten and captopril treated group; *: Statistically significant at $\mathrm{p} \leq 0.05$.

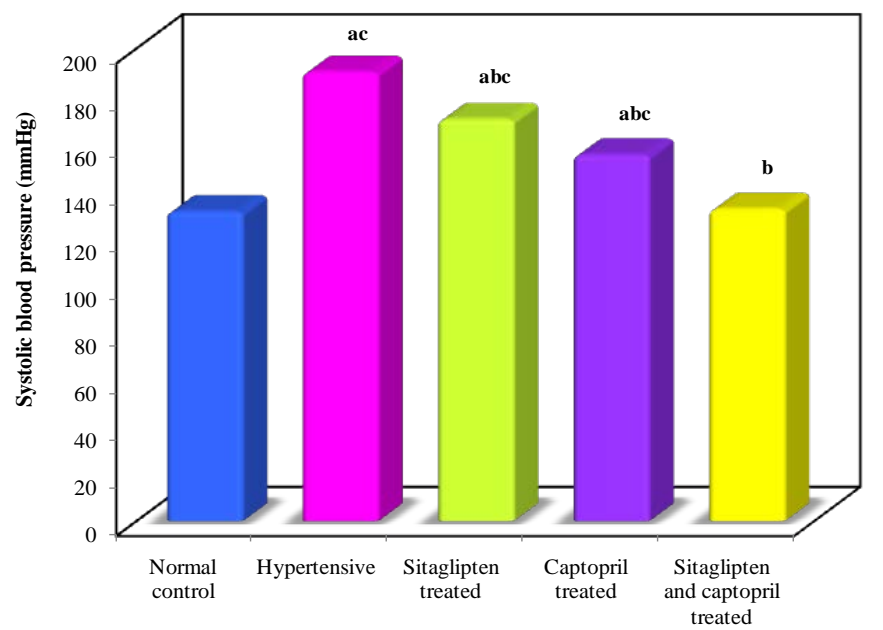

Figure 1. Effect of oral administration of sitaglipten and captopril separately or in combination daily for six weeks on systolic blood pressure.

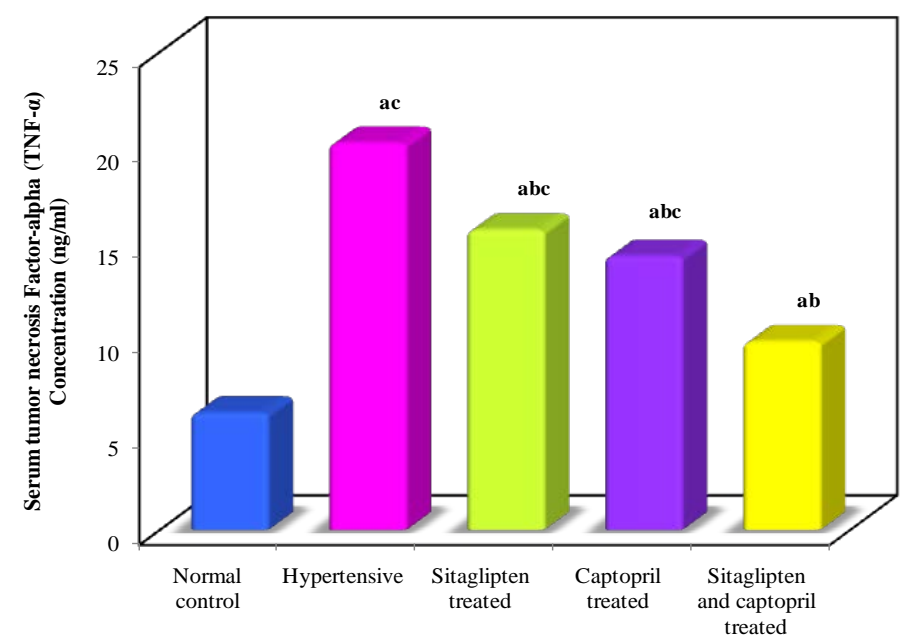

Figure 2. Effect of oral administration of sitaglipten and captopril separately or in combination daily for six weeks on serum tumor necrosis factor-alpha. 


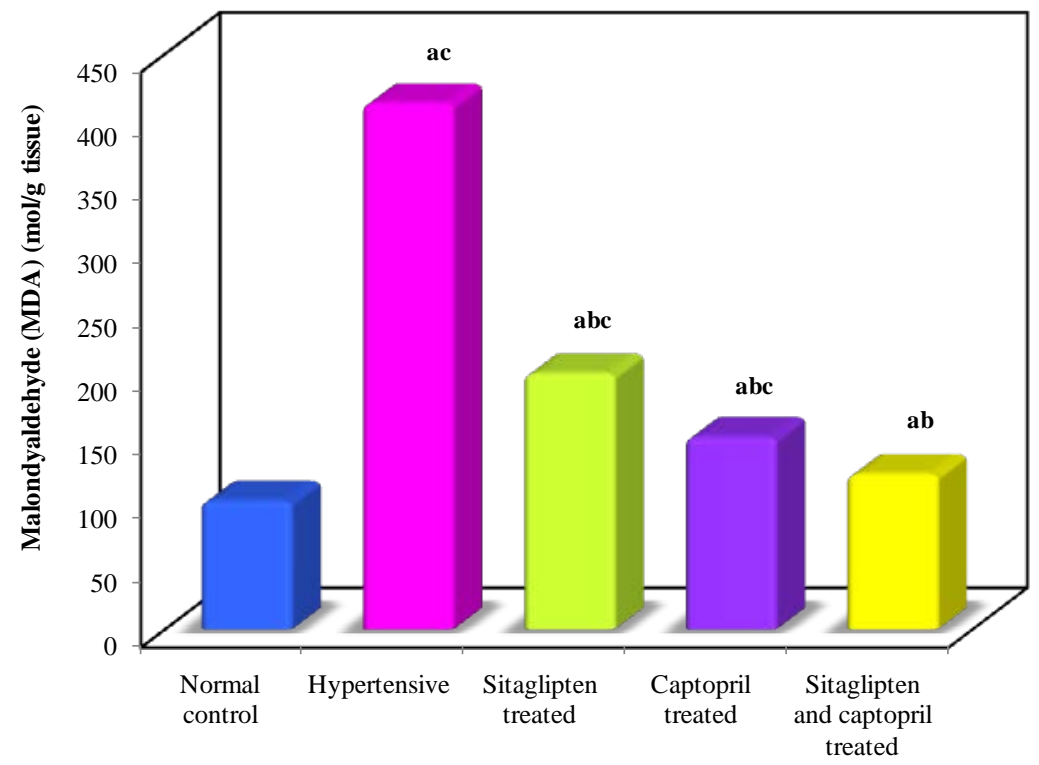

Figure 3. Effect of oral administration of sitaglipten and captopril separately or in combination daily for six weeks on malondialdyhyde.

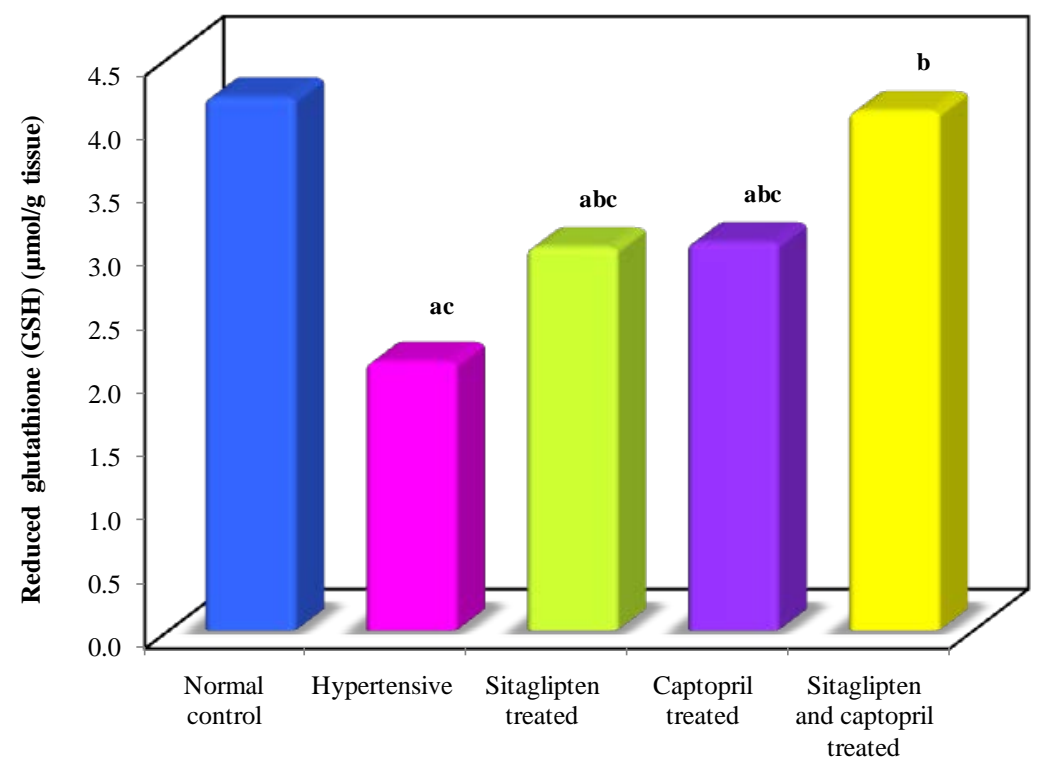

Figure 4. Effect of oral administration of sitaglipten and captopril separately or in combination daily for six weeks on reduced glutathione.

\subsection{Contraction Response to PE (Table 2)}

Cumulative addition of PE to organ bath resulted in concentration dependent contraction of aortas of all groups. There was a significant increase in maximal response of PE in hypertensive untreated groups, as compared to normal control group. Treatment with sitaglipten and captopril separately attenuated maximal response to PE significantly. Still the combination therapy gives better effect (Figure 5).

Body Weight, Heart Weight and Heart Weight/Body Weight Ratio (HW/BW Ratio, an Index of Cardiac Hypertrophy) (Table 3) (Figure 6, Figure 7, Figure 8).

Seven weeks intake of L-NAME resulted in a significant increase in HW/BW ratio when compared to control group. Sitaglipten and captopril significantly decreased cardiac hypertrophy in these groups. 
Table 2. Effect of oral administration of sitaglipten and captopril separately or in combination daily for six weeks on vascular reactivity in L-NAME-induced hypertensive rats (Mean $\pm \mathrm{SD}$ ).

\begin{tabular}{cc}
\hline Group $(\mathbf{n}=\mathbf{2 0})$ & Max Contract \\
\hline Control normal & $2.15 \pm 0.15$ \\
L-NAME untreated hypertensive gp. & $4.34 \pm 0.22^{\mathrm{ac}}$ \\
Sitaglipten treated gp. & $2.45 \pm 0.17^{\mathrm{abc}}$ \\
Captopril treated gp. & $2.37 \pm 0.32^{\mathrm{abc}}$ \\
Sitaglipten and captopril treated gp. & $1.98 \pm 0.16^{\mathrm{b}}$ \\
F (p) & $201.552^{*}(<0.001)$ \\
\hline
\end{tabular}

F: F test (ANOVA); a: Significant as compared to normal control group; b: Significant as compared to hypertensive group; c: Significant as compared to sitaglipten and captopril treated group; : : Statistically significant at $\mathrm{p} \leq 0.05$.

Table 3. Effect of oral administration of sitaglipten and captopril separately or in combination daily for six weeks on HW/ $\mathrm{BW}$ ratio in L-NAME-induced hypertensive rats (Mean $\pm \mathrm{SD}$ ).

\begin{tabular}{cccc}
\hline $\begin{array}{c}\text { Parameters Group Studied } \\
\text { (N = 20) }\end{array}$ & $\begin{array}{c}\text { Body Weight } \\
\text { B.W. (g) }\end{array}$ & $\begin{array}{c}\text { Heart Weight } \\
\text { H.W. }(\mathbf{m g})\end{array}$ & $\begin{array}{c}\text { HW/BW Ratio } \\
(\mathbf{m g} / \mathbf{g})\end{array}$ \\
\hline Normal control gp & $245 \pm 15.4$ & $1150 \pm 21.75$ & $4.69 \pm 1.41$ \\
Hypertensive gp. & $243 \pm 19.6$ & $1770 \pm 19.32^{\mathrm{ac}}$ & $7.28 \pm 0.99^{\mathrm{a}}$ \\
Sitaglipten treated gp. & $243 \pm 20.6$ & $1360 \pm 23.4^{\mathrm{abc}}$ & $5.60 \pm 1.136^{\mathrm{b}}$ \\
Captopril treated gp. & $244 \pm 16.7$ & $1359 \pm 18.9^{\mathrm{abc}}$ & $5.57 \pm 1.13^{\mathrm{b}}$ \\
Sitaglipten and captopril treated gp. & $246 \pm 15.8$ & $1200 \pm 21.8^{\mathrm{ab}}$ & $4.88 \pm 1.38^{\mathrm{b}}$ \\
F (p) & $0.054(0.994)$ & $1333.452^{*}(<0.001)$ & $7.006^{*}(<0.001)$ \\
\hline
\end{tabular}

F: F test (ANOVA); a: Significant as compared to normal control group; b: Significant as compared to hypertensive group; c: Significant as compared to sitaglipten and captopril treated group; ${ }^{*}$ : Statistically significant at $\mathrm{p} \leq 0.05$.

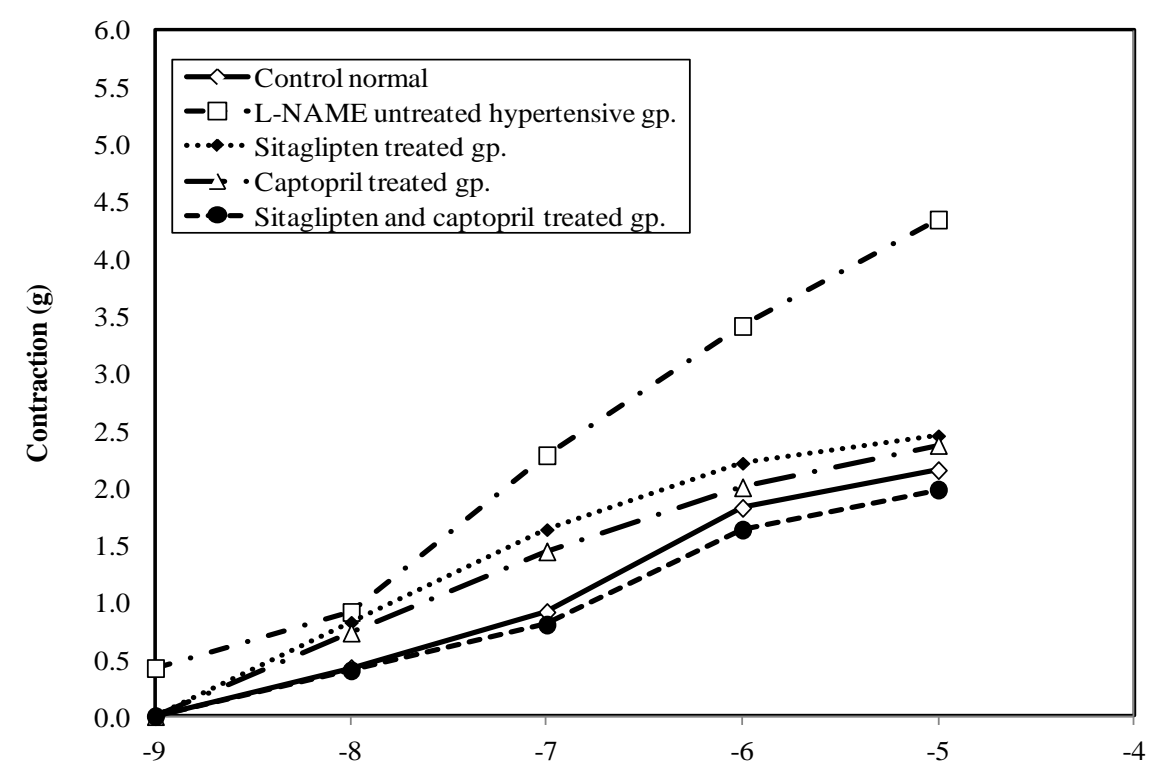

Figure 5. Effect of oral administration of sitaglipten and captopril separately or in combination daily for six weeks on vascular reactivity. 


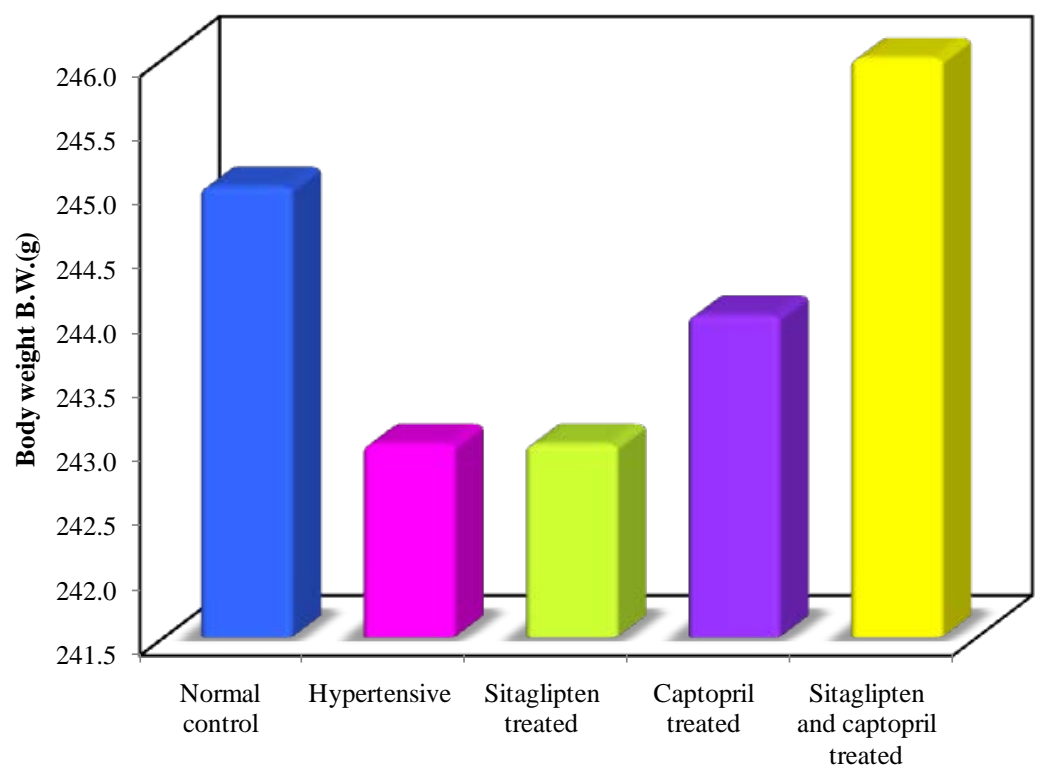

Figure 6. Effect of oral administration of sitaglipten and captopril separately or in combination daily for six weeks on body weight.

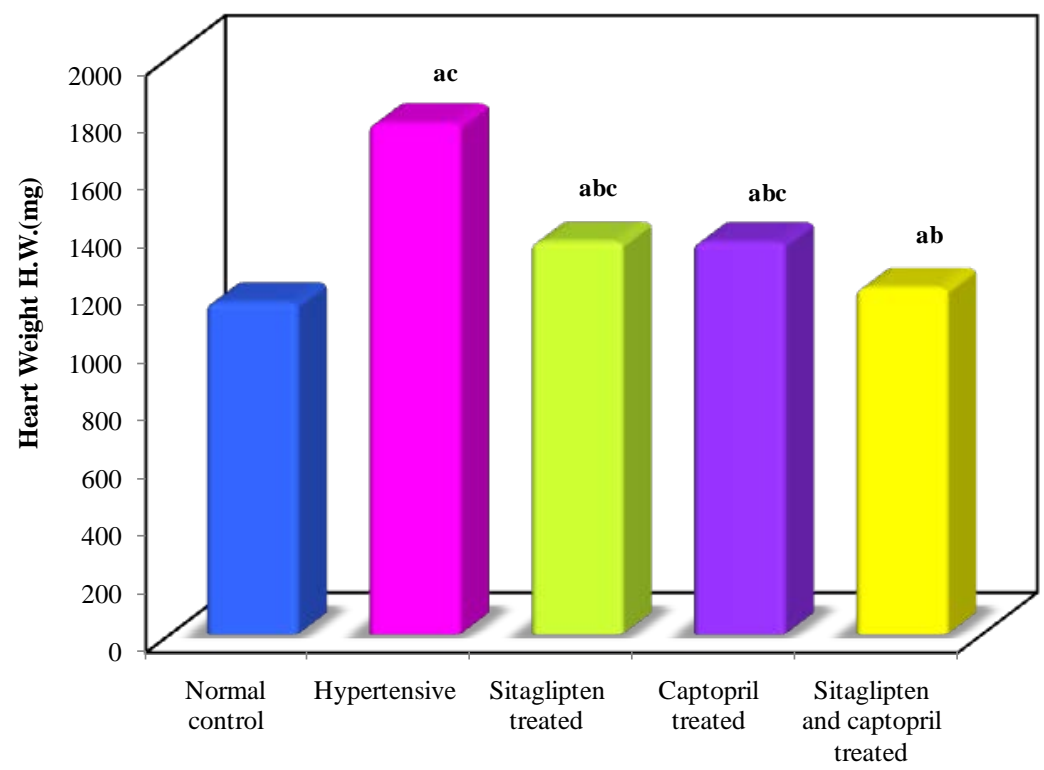

Figure 7. Effect of oral administration of sitaglipten and captopril separately or in combination daily for six weeks on heart weight.

\section{Discussion}

Hypertension is caused by pathological changes in renal and vascular structure and function that can cause renal damage if it is not properly controlled. Persistent hypertension is usually associated with diminished production and function of endothelium-derived nitric oxide (NO). Decreased NO leads to endothelial dysfunction, a crucial initial step culminating in vascular events in hypertension [23].

Glycemic and BP control are additive in improved outcomes in subjects with type IIDM. An analysis of the United Kingdom Prospective Diabetes Study demonstrated that any reduction in systolic blood pressure (SBP) is likely to reduce the risk of complications in subjects with type IIDM. A 10-mm Hg (6.5\%) reduction in SBP was associated with $11 \%$ reduction in any diabetes related endpoint, including stroke (18\%) and myocardial in- 


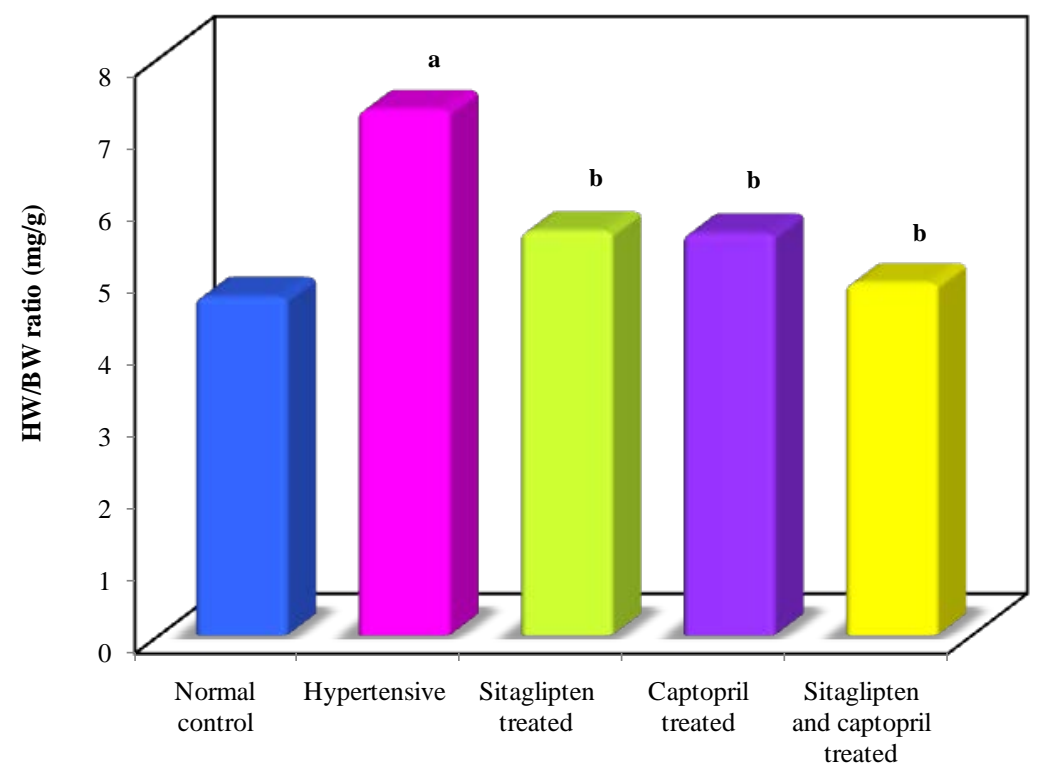

Figure 8. Effect of oral administration of sitaglipten and captopril separately or in combination daily for six weeks on HW/BW ratio.

farction (11\%) [24] [25]. In this study, chronic administration of L-NAME, an inhibitor of NO synthesis, produces systemic arterial hypertension, increases the level of serum TNF- $\alpha$, oxidative stress, vascular reactivity to $\mathrm{PE}$, and HW/BW ratio. In agreement with these results, studies stated that blockade of NO upregulated the expression of cell adhesion molecules in the endothelium with increase level of oxidative stress in endothelial cells and smooth muscle cells. Infiltration by inflammatory cells, mainly macrophages, in perivascular areas and in the intima could lead to fibrosis via the production of profibrotic cytokines [26] [27].

An increasing body of clinical evidence indicates that incretin-based therapies not only lower fasting and postprandial glucose, but also improve a wide variety of traditional cardiovascular risk factors including obesity, high blood pressure as well as fasting and postprandial lipid and apolipoprotein concentrations. Importantly, the effect of incretins on postprandial lipid excursions appears acute and therefore may be additive to lipid benefits of decreased appetite and body weight reduction that are characteristic of more chronic therapy with incretins or incretin analogues [28] [29].

GLP-1 has been found to exert cardioprotective effects in experimental models of dilated cardiomyopathy, hypertensive heart failure and myocardial infarction (MI) [30].

The present study demonstrated the importance of GLP-1 and GLP-1R in the regulation of endothelial function in hypertensive rats. Sitaglipten produced a significant decrease in BP, serum TNF- $\alpha$ and oxidative stress as compared to hypertensive untreated group. In addition, it reduced HW/BW ratio and attenuated the enhanced contractility to PE. Concerning the effect of sitaglipten on BP, clinical and experimental studies suggest that GLP-1 and its analogs confer cardiovascular protection through favorable modulation of blood pressure and cardiac hemodynamic responses [31] [32]. Also, others stated that GLP-1 reduced vascular tone, presumably mediated by nitric oxide and an intact endothelium [33]. However, other study suggested the possibility of endothelium-independent relaxant effects [34]. In humans, activation of the GLP-1 receptor resulted in vasodilation of brachial arteries and improved endothelial dysfunction in subjects with type IIDM with coronary heart disease [35].

These reports suggest direct activation of the GLP-1 receptor in peripheral endothelial tissue, mediating vasodilatory effects, as a possible mechanism Liu L, et al. [36] suggested the role of the GLP-1R and cAMP in the actions of GLP-1 on vascular endothelium. Another study suggests that DPP-4 inhibition by sitagliptin attenuates blood pressure elevation in young spontaneous hypertensive rats (SHRs) by diminishing proximal tubule sodium reabsorption and increased renal blood flow (RBF) in SHRs, which may in part contribute to the blood pressure-lowering effect of sitagliptin [37]. Of great relevance, pharmacological levels of GLP-1 improved endothelial function in healthy individuals as well as in T2DM patients with stable coronary artery disease and 
had a protective effect on postprandial endothelial function [38]. Moreover, some experimental data in humans show that increased GLP-1 activity may directly stimulate endothelial-mediated vasodilation independently of known metabolic actions of GLP-1 [39]. GLP-1 attenuated atherosclerotic lesions in mice model of atherosclerosis. The attenuation was associated with reduced monocyte/macrophage accumulation in the arterial wall indicating that suppression of vascular inflammation may represent another direct cardiovascular benefit of incretin-based therapy [40]. To explain the antioxidant effect of sitaglipten in the present study, in vitro study showed that, GLP-1 inhibited tumor necrosis factor alpha (TNF- $\alpha$ ) induced plasminogen activator inhibitor 1 (PAI-1) gene and protein expression in endothelial cells [41]. Ferreira et al. [42] demonstrated that the activity of the antioxidant enzymes, superoxide dismutase (SOD) and catalase were higher in animals treated with sitaglipten and nuclear oxidative stress was reduced. In addition, they demonstrated beneficial effects of sitagliptin on metabolic profile and reduction in inflammatory markers, as well as an amelioration of fibrosis, vacuolization, and congestion in pancreas and preservation of pancreatic islets [42]. Other results have been suggesting an antioxidant and anti-inflammatory effect of incretin modulators, due to attenuation of the deleterious effects of advanced glycosylated end products and its receptors (AGEs-RAGE oxidative stress axis) and to protection against the cytokine-induced apoptosis and necrosis [43] [44].

In addition to these antioxidant and vascular effects, GLP-1 or GLP-1 receptor agonists demonstrated multiple beneficial actions on the heart including protection of myocardium from ischemia in rats, improvement of cardiac function in rats with congestive heart failure [45]. Preliminary clinical studies also suggest that GLP-1 infusion may improve cardiac contractile function in chronic heart failure patients with and without diabetes, and in MI patients after successful angioplasty [46] [47].

DPP4 inhibitors administration decreased cardiac mRNA levels of BNP, a marker of left ventricular dysfunction and reduced cardiac mRNA expression of fibrosis markers, such as transforming growth factor b (TGF-b1), tissue inhibitor of matrix metalloproteinases (TIMP-1) and collagen (Col1a1 \& Col3a1) in uremic rats to baseline levels. The authors stated that, DPP-4 inhibitor, linagliptin, normalizes the mRNA expression of all of the key factors of cardiomyopathy, (TIMP-1) (Col3a1) to baseline level [48]. Other demonstrated that short-term treatment with all DPP-4 inhibitors (linagliptin, sitagliptin and alogliptin) decreases the plasma concentration of the vascular calcification marker, osteopontin. Osteopontin is known to be associated with vascular calcification and cardiovascular morbidity in humans [49].

The potential antifibrotic effects of DPP-4 inhibitors could provide an additional benefit for patients with heart diseases that very often accompany diabetics and may provide new therapy options for this class of drugs [50]. However, the results of ongoing studies will clarify whether incretin-based therapies live up to their promise as cardiovascular protective agents. Evidence has demonstrated the importance of RAS in diabetes-induced cardiac dysfunction [51]-[52]. Renin, angiotensinogen, angiotensin converting enzyme (ACE), angiotensin II (AGT II) receptors are expressed in the heart [52]. Hyperglycemia activates intra-cardiac RAS that has various effects on the myocardial cells. AGT II has a direct effect on cell signaling that results in hypertrophy in cardiac myocytes and proliferation of cardiac fibroblasts [53].

\section{Conclusion}

In conclusion, these data suggest that DPP-4 inhibitors and ACE inhibitors contribute to normal regulation of blood pressure and exert protective actions in hypertension.

\section{Acknowledgements}

The authors gratefully acknowledge the grant of center of scientific research and revival of Islamic heritage No: 43409031.

\section{Perspectives}

The findings of the present study highlight the prospect for the use of DPP4 inhibitors against vascular dysfunction in hypertension.

\section{References}

[1] Verma, A. and Solomon, S.D. (2009) Diastolic Dysfunction as a Link between Hypertension and Heart Failure. Medi- 
cal Clinics of North America, 93, 647-664. http://dx.doi.org/10.1016/j.mcna.2009.02.013

[2] Sciarretta, S., Paneni, F., Palano, F., Chin, D., Tocci, G., Rubattu, S. and Volpe, M. (2009) Role of the Renin-AngiotensinAldosterone System and Inflammatory Processes in the Development and Progression of Diastolic Dysfunction. Clinical Science, 116, 467-477. http://dx.doi.org/10.1042/CS20080390

[3] Reboldi, G., Gentile, G., Angeli, F. and Verdecchia, P. (2009) Choice of ACE Inhibitor Combinations in Hypertensive Patients with Type 2 Diabetes: Update after Recent Clinical Trials. Vascular Health and Risk Management, 5, 411-427. http://dx.doi.org/10.2147/VHRM.S4235

[4] Van Heerebeek, L., Somsen, A. and Paulus, W.J. (2009) The Failing Diabetic Heart: Focus on Diastolic Left Ventricular Dysfunction. Current Diabetes Reports, 9, 79-86. http://dx.doi.org/10.1007/s11892-009-0014-9

[5] Drucker, D.J. (2007) The Role of Gut Hormones in Glucose Homeostasis. Journal of Clinical Investigation, 117, $24-32$. http://dx.doi.org/10.1172/JCI30076

[6] Nikolaidis, L.A., Sunil Mankad, S., Sokos, G.G., Miske, G., Shah, A., Elahi, D. and Shannon, R.P. (2004) Effects of Glucagon-Like Peptide-1 in Patients with Acute Myocardial Infarction and Left Ventricular Dysfunction after Successful Reperfusion. Circulation, 109, 962-965. http://dx.doi.org/10.1161/01.CIR.0000120505.91348.58

[7] Yu, M., Moreno, C., Hoagland, K.M., Dahly, A., Ditter, K., Mistry, M. and Roman, R.J. (2003) Antihypertensive Effects of Glucagon-Like Peptide-1 in Dahl Salt-Sensitive rats. Journal of Hypertension, 21, 1125-1135. http://dx.doi.org/10.1097/00004872-200306000-00012

[8] Garber, A.J. (2012) Novel GLP-1 Receptor Agonists for Diabetes. Expert Opinion on Investigational Drugs, 21 , 45-57. http://dx.doi.org/10.1517/13543784.2012.638282

[9] Chang, G., Zhang, P., Ye, L., Lu, K., Wang, Y., Duan, Q., et al. (2013) Protective Effects of Sitagliptin on Myocardial Injury and Cardiac Function in an Ischemia/Reperfusion Rat Model. European Journal of Pharmacology, 718, 105113.

[10] Henrion, D., Dechaux, E., Dowell, F.J., Maclouf, J., Samuel, J., Levy, B.I. and Michel, J.B. (1997) Alteration of FlowInduced Dilatation in Mesenteric Resistance Arteries of L-NAME Treated Rats and Its Partial Association with Induction of Cyclo-Oxygenase-2. British Journal of Pharmacology, 121, 83-90. http://dx.doi.org/10.1038/sj.bjp.0701109

[11] Khan, B.V., Harrison, D.G., Olbrych, M.T., Alexander, R.W. and Medford, R.M. (1996) Nitric Oxide Regulates Vascular Cell Adhesion Molecule 1 Gene Expression and Redox-Sensitive Transcriptional Events in Human Vascular Endothelial Cells. Proceedings of the National Academy of Sciences, 93, 9114-9119. http://dx.doi.org/10.1073/pnas.93.17.9114

[12] Bernatova, I., Pechanova, O. and Simko, F. (1994) Effect of Captopril in L-NAME-Induced Hypertension on the Rat Myocardium, Aorta, Brain and Kidney. Experimental Physiology, 84, 1095-1105. http://dx.doi.org/10.1017/S0958067099018904

[13] Bose, A.K., Mocanu, M.M., Carr, R.D. and Yellon, D.M. (2005) Glucagon Like Peptide-1 Is Protective against Myocardial Ischemia/Reperfusion Injury When Given Either as a Preconditioning Mimetic or at Reperfusion in an Isolated Rat Heart Model. Cardiovascular Drugs and Therapy, 19, 9-11. http://dx.doi.org/10.1007/s10557-005-6892-4

[14] Freslon, J.L. and Giudicelli, J.F. (1983) Compared Myocardial and Vascular Effects of Captopril and Dihydralazine during Hypertension Development in Spontaneously Hypertensive Rats. British Journal of Pharmacology, 80, 533-543. http://dx.doi.org/10.1111/j.1476-5381.1983.tb10726.x

[15] Riley, V. (1960) Adaptation of Orbital Bleeding Technique to Rapid Serial Blood Studies. Experimental Biology and Medicine, 104, 751-755. http://dx.doi.org/10.3181/00379727-104-25975

[16] Mattson, D.L. (1998) Long-Term Measurement of Arterial Blood Pressure in Conscious Mice. American Journal of Physiology-Regulatory, Integrative and Comparative Physiology, 274, R564-R570.

[17] Aukrust, P., Libak, N.B., Muller, F., Lien, E., Espevik, T. and Frøland, S.S. (1994) Serum Levels of Tumor Necrosis Factor- $\alpha$ (TNF- $\alpha$ ) and Soluble TNF Receptors in Human Immunodeficiency Virus Type 1 Infection, Correlations to Clinical Immunologic and Virologic Parameters. Journal of Infectious Diseases, 169, 420-424. http://dx.doi.org/10.1093/infdis/169.2.420

[18] Ohkawa, H., Ohishi, M. and Yagi, K. (1979) Assay for Lipid Peroxides in Animal Tissues by Thiobarbituric Acid Reaction. Analytical Biochemistry, 95, 351-358. http://dx.doi.org/10.1016/0003-2697(79)90738-3

[19] Ellman, G.I. (1959) Tissue Sulfhydryl Groups. Archives of Biochemistry and Biophysics, 82, 70-77. http://dx.doi.org/10.1016/0003-9861(59)90090-6

[20] Satoh, H. and Satoh, S. (1984) Prostaglandine $E_{2}$ and $I_{2}$ Production in Isolated Renal Arteries in Absence or Presence of Vascular Endothelial Cells. Biochemical and Biophysical Research Communications, 188, 873-876. http://dx.doi.org/10.1016/0006-291X(84)91476-1

[21] Brooks, W.W., Bing, O.H.L., Robinson, K.G., Slawsky, M.T., Chaletsky, D.M. and Conard, C.H. (1997) Effect of An- 
giotensin-Converting Enzyme Inhibition on Myocardial Fibrosis and Function in Hypertrophied and Failing Myocardium from the Spontaneously Hypertensive Rat. Circulation, 96, 4002-4010.

http://dx.doi.org/10.1161/01.CIR.96.11.4002

[22] Hill, B.A. (1971) Principles of Medical Statistics. 9th Edition, Lancet Limited Publications, London, $147,383$.

[23] Lorber, D. (2012) GLP-1 Receptor Agonists: Effects on Cardiovascular Risk Reduction. Cardiovascular Therapeutics, 31, 238-249.

[24] Wong, W.T., Wong, S.L., Tian, X.Y. and Huang, Y. (2010) Endothelial Dysfunction: The Common Consequence in Diabetes and Hypertension. Journal of Cardiovascular Pharmacology, 55, 300-307. http://dx.doi.org/10.1097/FJC.0b013e3181d7671c

[25] Stratton, I.M., Cull, C.A., Adler, A.I., Matthews, D.R., Neil, H.A. and Holman, R.R. (2006) Additive Effects of Glycaemia and Blood Pressure Exposure on Risk of Complications in Type 2 Diabetes: A Prospective Observational Study (UKPDS 75). Diabetologia, 49, 1761-1769. http://dx.doi.org/10.1007/s00125-006-0297-1

[26] Chinda, K., Palee, S., Surinkaew, S., Phornphutkul, M., Chattipakorn, S. and Chattipakorn, N. (2013) Cardioprotective Effect of Dipeptidyl Peptidase-4 Inhibitor during Ischemia-Reperfusion Injury. International Journal of Cardiology, 167, 451-457. http://dx.doi.org/10.1016/j.ijcard.2012.01.011

[27] Huisamen, B., Genis, A., Marais, E. and Lochner, A. (2011) Pre-Treatment with a DPP-4 Inhibitor Is Infarct Sparing in Hearts from Obese, Pre-Diabetic Rats. Cardiovascular Drugs and Therapy, 25, 13-20. http://dx.doi.org/10.1007/s10557-010-6271-7

[28] Schwartz, E.A., Koska, J., Mullin, M.P., Syoufi, I., Schwenke, D.C. and Reaven, P.D. (2010) Exenatide Suppresses Postprandial Elevations in Lipids and Lipoproteins in Individuals with Impaired Glucose Tolerance and Recent Onset Type 2 Diabetes Mellitus. Atherosclerosis, 212, 217-222. http://dx.doi.org/10.1016/j.atherosclerosis.2010.05.028

[29] Grieve, D.J., Cassidy, R.S. and Green, B.D. (2009) Emerging Cardiovascular Actions of the Incretin Hormone Glucagon-Like Peptide-1: Potential Therapeutic Benefits beyond Glycaemic Control? British Journal of Pharmacology, 157, 1340-1351. http://dx.doi.org/10.1111/j.1476-5381.2009.00376.x

[30] Ku, H.C., Chen, W.P. and Su, M.J. (2010) GLP-1 Signaling Preserves Cardiac Function in Endotoxemic Fischer 344 and DPP4-Deficient Rats. Naunyn-Schmiedeberg's Archives of Pharmacology, 382, 463-474. http://dx.doi.org/10.1007/s00210-010-0559-9

[31] Mundil, D., Cameron-Vendrig, A. and Husain, M. (2012) GLP-1 Receptor Agonists: A Clinical Perspective on Cardiovascular Effects. Diabetes and Vascular Disease Research, 9, 95-108. http://dx.doi.org/10.1177/1479164112441526

[32] Gill, A., Hoogwerf, B.J., Burger, J., Bruce, S., Macconell, L., Yan, P., Braun, D., Giaconia, J. and Malone, J. (2010) Effect of Exenatide on Heart Rate and Blood Pressure in Subjects with Type 2 Diabetes Mellitus: A Double-Blind, Placebo Controlled, Randomized Pilot Study. Cardiovascular Diabetology, 9, 16.

[33] Scheen, A.J. (2012) Cardiovascular Effects of Gliptins. Nature Reviews. Cardiology, 10, 73-84.

[34] Kim, M., Platt, M.J., Shibasaki, T., Quaggin, S.E., Backx, P.H., Seino, S., Simpson, J.A. and Drucker, D.J. (2013) GLP-1 Receptor Activation and Epac2 Link Atrial Natriuretic Peptide Secretion to Control of Blood Pressure. Nature Medicine, 19, 567-575. http://dx.doi.org/10.1038/nm.3128

[35] Read, P.A., Hoole, S.P., White, P.A., Khan, F.Z., O’Sullivan, M., West, N.E. and Dutka, D.P. (2011) A Pilot Study to Assess Whether Glucagon-Like Peptide-1 Protects the Heart from Ischemic Dysfunction and Attenuates Stunning after Coronary Balloon Occlusion in Humans. Circulation: Cardiovascular Interventions, 4, 266-272. http://dx.doi.org/10.1161/CIRCINTERVENTIONS.110.960476

[36] Liu, L., Liu, J., Wong, W.T., Tian, X.Y., Lau, C.W., Wang, Y.X., et al. (2012) Dipeptidyl Peptidase 4 Inhibitor Sitagliptin Protects Endothelial Function in Hypertension through a Glucagon-Like Peptide 1-Dependent Mechanism. Hypertension, 60, 833-841. http://dx.doi.org/10.1161/HYPERTENSIONAHA.112.195115

[37] Pacheco, B.P., Crajoinas, R.O., Couto, G.K., Davel, A.P., Lessa, L.M., Rossoni, L.V. and Girardi, A.C. (2011) Dipeptidyl Peptidase IV Inhibition Attenuates Blood Pressure Rising in Young Spontaneously Hypertensive Rats. Journal of Hypertension, 29, 520-528. http://dx.doi.org/10.1097/HJH.0b013e328341939d

[38] Ceriello, A., Esposito, K., Testa, R., Bonfigli, A.R., Marra, M. and Giugliano, D. (2011) The Possible Protective Role of Glucagon-Like Peptide 1 on Endothelium During the Meal and Evidence for an "Endothelial Resistance" to Glucagon-Like Peptide 1 in Diabetes. Diabetes Care, 34, 697-702. http://dx.doi.org/10.2337/dc10-1949

[39] Koska, J., Schwartz, E.A., Mullin, M.P., Schwenke, D.C. and Reaven, P.D. (2010) Improvement of Postprandial Endothelial Function after a Single Dose of Exenatide in Individuals with Impaired Glucose Tolerance and Recent-Onset Type 2 Diabetes. Diabetes Care, 33, 1028-30. http://dx.doi.org/10.2337/dc09-1961

[40] Arakawa, M., Mita, T., Azuma, K., Ebato, C., Goto, H., Nomiyama, T., Fujitani, Y., Hirose, T., Kawamori, R. and Watada, H. (2010) Inhibition of Monocyte Adhesion to Endothelial Cells and Attenuation of Atherosclerotic Lesion by a Glucagon-Like Peptide-1 Receptor Agonist, Exendin-4. Diabetes, 59, 1030-1037. 
http://dx.doi.org/10.2337/db09-1694

[41] Liu, H., Hu, Y., Simpson, R.W. and Dear, A.E. (2008) Glucagon-Like Peptide-1 Attenuates Tumour Necrosis Factor-Alpha-Mediated Induction of Plasmogen Activator Inhibitor-1 Expression. Journal of Endocrinology, 196, 57-65. http://dx.doi.org/10.1677/JOE-07-0387

[42] Ferreira, L., Teixeira-De-Lemos, E., Pinto, F., Parada, B., Mega, C., Vala, H., et al. (2010) Effects of Sitagliptin Treatment on Dysmetabolism, Inflammation, and Oxidative Stress in an Animal Model of Type 2 Diabetes (ZDF Rat). Mediators of Inflammation, 2010, Article ID: 592760.

[43] Matsui, T., Nishino, Y., Takeuchi, M. and Yamagishi, S.I. (2011) Vildagliptin Blocks Vascular Injury in Thoracic Aorta of Diabetic Rats by Suppressing Advanced Glycation End Product-Receptor Axis. Pharmacological Research, 63, 383-388. http://dx.doi.org/10.1016/j.phrs.2011.02.003

[44] Zhang, X., Wang, Z., Huang, Y. and Wang, J. (2011) Effects of Chronic Administration of Alogliptin on the Development of Diabetes and $\beta$-Cell Function in High Fat Diet/Streptozotocin Diabetic Mice. Diabetes, Obesity and Metabolism, 13, 337-347. http://dx.doi.org/10.1111/j.1463-1326.2010.01354.x

[45] Liu, Q., Anderson, C., Broyde, A., Polizzi, C., Fernandez, R., Baron, A. and Parkes, D.G. (2010) Glucagon-Like Peptide-1 and the Exenatide Analogue AC3174 Improve Cardiac Function, Cardiac Remodeling, and Survival in Rats with Chronic Heart Failure. Cardiovascular Diabetology, 9, 76. http://dx.doi.org/10.1186/1475-2840-9-76

[46] Ossum, A., van Deurs, U., Engstrom, T., Jensen, J.S. and Treiman, M. (2009) The Cardioprotective and Inotropic Components of the Postconditioning Effects of GLP-1 and GLP-1(9-36)a in an Isolated Rat Heart. Pharmacological Research, 60, 411-417. http://dx.doi.org/10.1016/j.phrs.2009.06.004

[47] Best, J.H., Hoogwerf, B.J., Herman, W.H., Pelletier, E.M., Smith, D.B., Wenten, M. and Hussein, M.A. (2011) Risk of Cardiovascular Disease Events in Patients with Type 2 Diabetes Prescribed the Glucagon-Like Peptide 1 (GLP-1) Receptor Agonist Exenatide Twice Daily or Other Glucose-Lowering Therapies: A Retrospective Analysis of the Life Link Database. Diabetes Care, 34, 90-95. http://dx.doi.org/10.2337/dc10-1393

[48] Pfisterer, M., Buser, P., Rickli, H., Gutmann, M., Erne, P., et al. (2009) BNP-Guided vs Symptom-Guided Heart Failure Therapy: The Trial of Intensified vs Standard Medical Therapy in Elderly Patients with Congestive Heart Failure (TIMECHF) Randomized Trial. JAMA, 301, 383-392. http://dx.doi.org/10.1001/jama.2009.2

[49] Yan, X., Sano, M., Lu, L., Wang, W., Zhang, Q., Zhang, R.Y., Wang, L.J., Chen, Q.J., Fukuda, K. and Shen, W.F. (2010) Plasma Concentrations of Osteopontin, but Not Thrombin-Cleaved Osteopontin, Are Associated with the Presence and Severity of Nephropathy and Coronary Artery Disease in Patients with Type 2 Diabetes Mellitus. Cardiovascular Diabetology, 9, 70. http://dx.doi.org/10.1186/1475-2840-9-70

[50] Susana, R., Amaia, Z. and Diez, J. (2012) GLP-1 and Cardioprotection: From Bench to Bedside. Cardiovascular Research, 94, 1-8.

[51] Guleria, R.S., Choudhary, R., Tanaka, T., Baker, K.M. and Pan, J. (2011) Retinoic Acid Receptor-Mediated Signaling Protects Cardiomyocytes from Hyperglycemia Induced Apoptosis: Role of the Rennin Angiotensin System. Journal of Cellular Physiology, 226, 1292-1307. http://dx.doi.org/10.1002/jcp.22457

[52] Kumar, R., Yong, Q.C., Thomas, C.M. and Baker, K.M. (2012) Intracardiac Intracellular Angiotensin System in Diabetes. American Journal of Physiology-Regulatory, Integrative and Comparative Physiology, 302, R510-R517. http://dx.doi.org/10.1152/ajpregu.00512.2011

[53] Kurdi, M. and Booz, G.W. (2011) New Take on the Role of Angiotensin II in Cardiac Hypertrophy and Fibrosis. Hypertension, 57, 1034-1038. http://dx.doi.org/10.1161/hypertensionaha.111.172700 


\section{Abbreviations}

ACE: Angiotensin-converting enzyme.

AGEs-RAGE: Advanced glycosylated end products and its receptors

BP: Blood pressure.

Col1a1: Collagen.

DSS: Dahl salt-sensitive.

GLP-1: Glucagon-like peptide-1.

GSH: Reduced glutathione.

L-NAME: NG-nitro-L-arginine methyl ester.

LV: Left ventricular.

MDA: Malondialdehyde.

NOS: Nitric oxide synthase.

PAI-1: Plasminogen activator inhibitor 1.

RAAS: Renin-angiotensin-aldosterone system.

RBF: Renal blood flow.

TGF-b1: Transforming growth factor $b$.

TIMP-1: Tissue inhibitor of matrix metalloproteinases.

TNF- $\alpha$ : Tumor necrosis factor alpha 
Scientific Research Publishing (SCIRP) is one of the largest Open Access journal publishers. It is currently publishing more than 200 open access, online, peer-reviewed journals covering a wide range of academic disciplines. SCIRP serves the worldwide academic communities and contributes to the progress and application of science with its publication.

Other selected journals from SCIRP are listed as below. Submit your manuscript to us via either submit@scirp.org or Online Submission Portal.
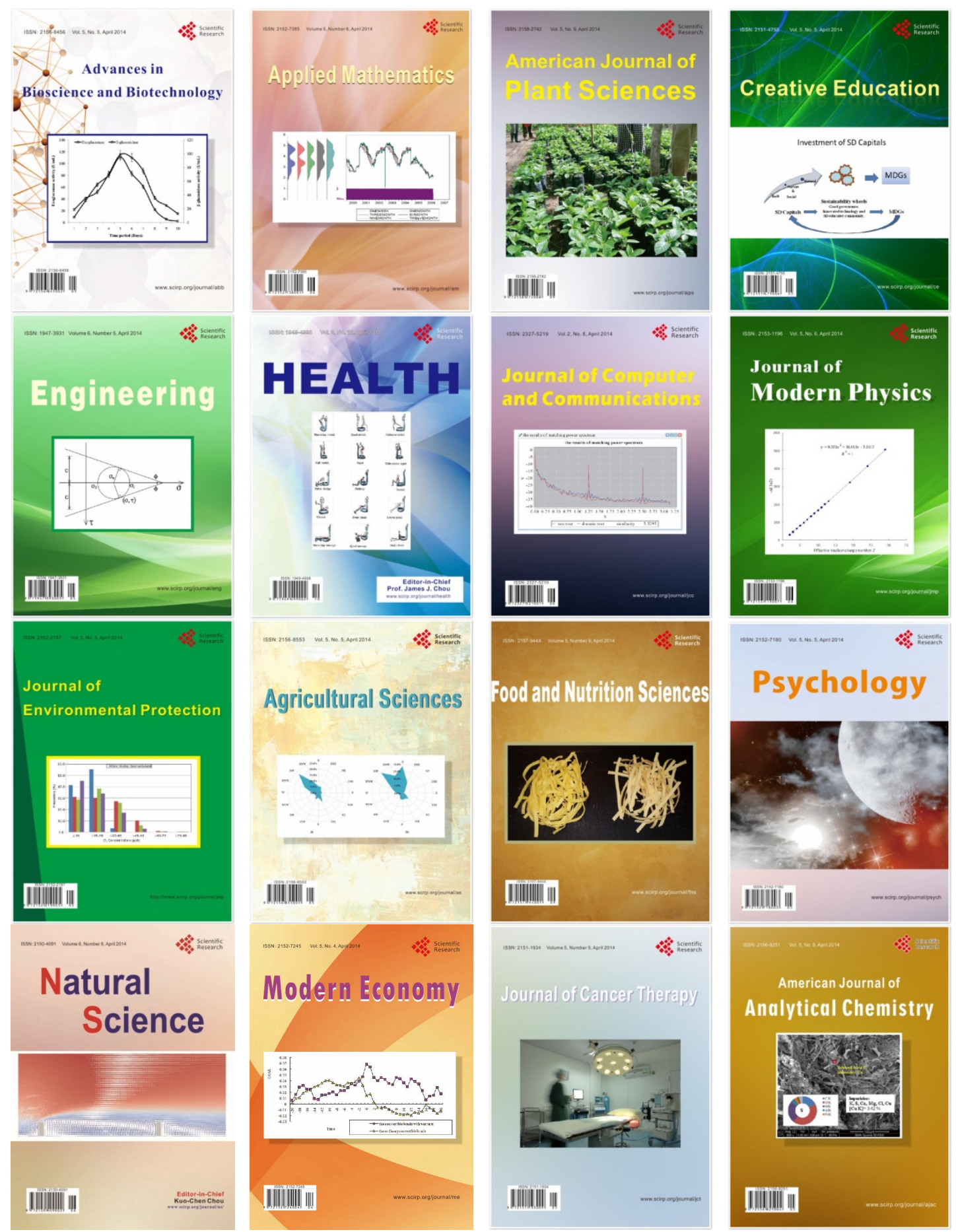